East African Medical Journal Vol. 86 No. 1 January 2009

MATERNAL MORTALITY AT THE STATE SPECIALIST HOSPITAL BAUCHI, NORTHERN NIGERIA

A G. Mairiga, MBBS, MHPM, FWACS, Senior Lecturer, Department of Obstetrics and Gynaecology, University of Maiduguri Teaching Hospital, P. M. B. 1414 Maiduguri, Nigeria, Visiting Consultant Obstetrician and Gynaecologist, State Specialist Hospital Bauchi, Bauchi, Nigeria and W. Saleh, MBBS, Principal Medical officer, Department of Obstetrics and Gynaecology, State Specialist Hospital Bauchi, P. M. B. 01 Bauchi, Bauchi state, Nigeria

Request for reprints to: Dr. A. G. Mairiga, Department of Obstetrics and Gynaecology, University of Maiduguri Teaching Hospital, P. M. B. 1414, Maiduguri, Nigeria

\title{
MATERNAL MORTALITY AT THE STATE SPECIALIST HOSPITAL BAUCHI, NORTHERN NIGERIA
}

\author{
A. G. MAIRIGA and W. SALEH
}

\begin{abstract}
Objective: To analyse and document our experiences with maternal mortality with the view of finding the trends over the last seven years, common causes and attributing socio-demographic factors.

Design: A prospective analysis of maternal mortality.

Setting: State Specialists Hospital Bauchi, Bauchi Northeastern Nigeria.

Main outcome measures: These include maternal mortality ratio for the period under review and the annual trends, age and parity most affected the direct and indirect causes of maternal mortality in our environment.

Results: The Maternal Mortality Ratio (MMR) for the period under review was 1,732 per 100, 000 live births. Six hundred and twenty one of the deaths $(81.0 \%)$ occurred in 12,067 unbooked deliveries giving a maternal mortality ratio of 5,146 per 100,000 for unbooked mothers. This ratio is approximately eleven times that obtained in booked live deliveries. Age range was 14-44 years and the mean age was 27.8 years. The highest maternal death was in the adolescent mothers. The primigravidas had the highest maternal mortality of $28.9 \%$. The direct obstetric causes of maternal death accounted for $79.4 \%$ of the deaths. The major causes of deaths were eclampsia $31.9 \%$, haemorrhage $19.2 \%$ and sepsis $10.4 \%$. Amongst the indirect causes of maternal death, anaemia was the leading cause accounting for $12.1 \%$. The annual MMR was highest for the year $2006(2,586$ per 100,000).

Conclusion: Maternal mortality is unacceptably high in our environment. The provision of more health facilities where basic and comprehensive antenatal care are provided, skilled attendants at birth, community mobilisation to improve antenatal attendance and the use of TBAs as a link between the pregnant women, families and communities providing important messages for a healthy pregnancy, and safe birth remain the bedrock of containing maternal mortality in our environment.
\end{abstract}

\section{INTRODUCTION}

Maternal mortality refers to the death of a woman while pregnant or within 42 days of termination of pregnancy. Direct maternal death refers to the deaths resulting from complications of pregnancy, labour, puerperium and from interventions or any aftereffects of these complications such as bleeding after delivery. Indirect maternal death refers to the deaths resulting from the worsening of existing conditions by pregnancy or delivery, such as malaria, diabetes and renal diseases (1). Levels of maternal mortality are measured by the maternal mortality ratio, or the number of maternal deaths per 100,000 live births.
Over600,000 women die annually from complications during pregnancy, childbirth, or the postpartum period. Nearly all of thesedeathsoccurin developing countries, where fertility rates arehigher and a woman's life time risk of dying during pregnancy and childbirth is over 400 times higher than in developed countries $(2,3)$. Additionally, an estimated 20 million women endure life long disabilities such as pelvic pain, incontinence, obstetric fistula, anaemia and infertility. Pregnancy complications are the main cause of death for women aged 15-19 years (4). High maternal mortality rates in many countries result from poor reproductive health care, including nothaving access to skilled care during pregnancy. Risks of poor outcomes during pregnancy 
and childbirth are exacerbated by poverty, low status of women, lack of education, poor nutrition, heavy workloads and violence against women (5).

In Nigeria estimates indicated that there are 55,000 maternal deaths annually. Nigeria is only $2 \%$ of the world's population but accounts for over $10 \%$ of the world's maternal deaths (6). Nigeria ranks second globally (next to India) in number of maternal deaths (7). Risk of a woman dying from child birth is 1 in 18 in Nigeria; that for sub-Saharan Africa is 1:16 which compares very well for that of Nigeria, compared to 1 in 61 for all developing countries, and 1 in 29,800 for Sweden (a developed country) (3). For every woman who dies from childbirth in Nigeria, another 30 women suffer long term chronic ill-health.

Since theNairobi1987Safe Motherhood Initiatives, maternal mortality has received special interest from the global health and development agencies both at regional and global levels; yet appreciable reduction in the maternal mortality has not been achieved (8). This alarming global problem, sooner than later became a priority to both governments and concerned agencies worldwidewith maternal mortality becoming a top agenda in many international forums. A formal millennium summit to address a reduction in maternal mortality, among other world crucial issues, was adopted as an International Development Goal by Organisation for Cooperation and Economic Development, World Bank, United Nations (UN) and the International Monetary Fund (IMF). This was endorsed by 189 heads of states at the summit, which gave birth to the establishment of the Millennium DevelopmentGoal5(MDG5) in 2000, with the specific goal of reducing maternal mortality by $75 \%$ at theend of 2015 (9). Though some degree of reduction in maternal death has been achieved in the developed countries, no much progress was recorded in Africa and Asia (7).

In 2006, a new maternal mortality working group - which included WHO, UNICEF, UNFPA, The World Bank, and the United Nations Population Division (UNPD), as well as several outside technical experts - was established to work on the new round of estimates of maternal mortality for 2005 (10). The analysis of trends of maternal mortality by this working group shows that, at the global level, maternal mortality has decreased at an average of less than $1 \%$ annually between 1990 and 2005 - far below the 5.5\% annual decline, which is necessary to achieve the fifth MDG, concerning maternal mortality reduction. It has also been reported that for all countries with data, there was a decrease of $2.5 \%$ per year in the maternal mortality ratio between 1990 and 2005 ( $\mathrm{p}<0.0001)$; however, there was no evidence of a significant reduction in maternal mortality ratios in sub-Saharan Africa in the same period (11). Therefore, to achieve that goal, MMRs will need to decrease at a much faster rate in the future-especially in sub-Saharan Africa, where the annual decline has so far been approximately $0.1 \% 10$. Achieving this goal requires increased attention to improved health care for women, including high-quality emergency obstetric care.

The main objective of this study was to analyse and document our experience with maternal mortality with the view of finding the trend over the last seven years, common causes and attributing demographic factors. Suggestions on the ways of reducing the ever increasing scourge will be offered.

Study area: Bauchi State is located in the Northeastern region, occupying a land area of 49,259 square kilometers, which represents about $5.3 \%$ of Nigeria's total landmass (the state is about the third largest state in Nigeria in terms of land mass). Its population in 2006 was $4,676,463$ (12). Using the projection of a $2.8 \%$ growth rate, there are currently estimated 130,941 live deliveries annually.

In addition to a Federal Medical Center in Azare (northern Bauchi) and theSpecialist Hospital in Bauchi (Southern Bauchi), the State has 13 General Hospitals, 12 Cottage Hospitals, and 71 Primary Health Care Clinics. There are numerous privately owned clinics. The State has 86 secondary schools, five tertiary educational institutions, including two Colleges of Education, one School of Nursing, one School of Midwifery and a School of Health Technology.

The status of women in the State is still relatively low, compared to their male counterparts. This is reflected in the employment rate of $19 \%$ for women, against $87 \%$ for males. Women's limited access to conventional health care facilities, particularly emergency obstetric services, arises from lack of information needed at the household for making the rightdecisions regarding theirhealth. In the rural areas, bad roads and inadequate transportation compound this problem. The resultis a high maternal mortality rate of $1549 / 100,000$ live birth as against the national rate $704 / 100,000$. The total fertility rate (TFR) remains high at $6.8 \%$, against the $5.2 \%$ national rate (13). Another factor underlying maternal deaths in Bauchi State is the early age at sexual debut (15.3 years) and teenage pregnancy rate of $51.3 \%$. Only $1 \%$ of women in Bauchi State are delivered by Caesarean section as against $4 \%$ nationally. Seventy one per cent of households live 5 kilometers from the nearest health facility while $46 \%$ live within 15 kilometers from the nearest town (14).

\section{MATERIALS AND METHODS}

This was a prospective study of 767 maternal deaths recorded at the State Specialist Hospital Bauchi, Bauchi state Nigeria, over a period of seven years; from $1^{\text {st }}$ January 2001 to $31^{\text {st }}$ December 2007. One of the authors developed a format containing the required data on each maternal death. The author retrieved the case notes and extracted the required data within 24 hours of each maternal death and the data extracted were transferred onto the pre-formed format sheet. 
The data extracted included the age, parity, booking status, level of education, cause of death, time of arrival, time of death and the socio-cultural and economic circumstances surrounding the deaths. The data obtained was coded and transferred into an IBM compatible PC for analysis using SPSS version 11.0 for window statistical package. Frequency and descriptive statistics were computed

\section{RESULTS}

A total of 44,281 live deliveries occurred during the period (an average of 6,326 live deliveries annually) and there were 767 maternal deaths. The maternal mortality ratio (MMR) was 1,732 per 100,000 live births. Six hundred and twenty one of the deaths $(81.0 \%)$ occurred in 12,067 unbooked deliveries giving a maternal mortality ratio of 5,146 per 100,000 for unbooked mothers. This ratio is approximately eleven times that obtained in 31,614 booked live deliveries with 146 maternal deaths giving a MMR of 462 per 100,000. The highest maternal mortality ratio was recorded in the year 2006 and the lowest was in 2002 (Table 1).
Three hundred and sixty two of the patients (47.2\%) died within 24 hours of admission, $150(19.6 \%)$ died between 24 and 48 hours after admission, 88 (11.5\%) died between 48 and 72 hours of admission, while $167(21.0 \%)$ of the maternal deaths occurred more than 72 hours after admission into the hospital.

The age range was 15-45 years and the mean age was 27.8 years. The highest maternal death was in the adolescent mothers (28.9\%), and the lowest was those women above 44 years $(4.4 \%)$. The primigravidas had the highest maternal mortality of $42.2 \%$ and the grandmultiparous (Para 5 and above) had the lowest maternal mortality of $26.1 \%$ (Table 2).

Thedirectobstetriccauses of maternaldeathaccount for $79.4 \%$ of thedeaths, (Table3). Themajorcauses ofdeath were severe pre-eclampsia/eclampsia $31.9 \%$, obstetric haemorrhages $19.2 \%$ and sepsis $10.4 \%$. Over $50 \%$ of the obstetric haemorrhages were secondary to postpartum haemorrhage; which also contributed to nearly $10 \%$ of the total maternaldeathsover thestudy period.Anaemia, even though an indirect cause of maternal mortality, has contributed to $12.1 \%$ of the maternal deaths and for the last three years of the study period, it has been the second highest killer next to eclampsia as a single cause of maternal mortality (Table 4).

Table 1

Trends of maternal mortality

\begin{tabular}{lllllllll}
\hline Variables & 2001 & 2002 & 2003 & 2004 & 2005 & 2006 & 2007 & Total \\
\hline Maternal deaths & 81 & 92 & 125 & 124 & 84 & 150 & 111 & 767 \\
Total deliveries & 4,928 & 7,064 & 6,736 & 8,263 & 5,687 & 5,800 & 5,803 & 44,281 \\
Maternal mortality ratio & 1,644 & 1,302 & 1,856 & 1,501 & 1,477 & 2,586 & 1,913 & 1,732 \\
$\%$ differences over 2001 figure & -20.8 & +12.9 & -8.9 & 10.2 & +57.3 & +16.4 & +5.4 \\
\hline
\end{tabular}

Table 2

Socio-demographic characteristics

\begin{tabular}{lrr}
\hline & No. & $(\%)$ \\
\hline Age (years) & & \\
$<20$ & 222 & 28.9 \\
$20-24$ & 137 & 17.9 \\
$25-29$ & 189 & 24.6 \\
$30-34$ & 79 & 10.3 \\
$35-39$ & 56 & 7.3 \\
$40-44$ & 53 & 6.9 \\
$>44$ & 31 & 4.4 \\
Parity & & \\
1 & 324 & 42.2 \\
$2-4$ & 243 & 31.7 \\
$5+$ & 200 & 26.1 \\
Booking status & & \\
Yes & 146 & 19.0 \\
No & 621 & 81.0 \\
\hline
\end{tabular}


Table 3

Causes of maternal mortality

\begin{tabular}{lll}
\hline Cause & No. & $(\%)$ \\
\hline Direct causes & & \\
Pre-eclampsia/Eclampsia & 245 & 31.9 \\
Obstetric haemorrhage & 147 & 19.2 \\
PPH & 75 & 9.8 \\
Placenta praevia & 57 & 7.4 \\
Abruption placentae & 15 & 2.0 \\
Sepsis & 80 & 10.4 \\
Ruptured uterus/obstructed labor & 60 & 07.8 \\
Unsafe abortion & 48 & 06.3 \\
Ruptured Ectopic pregnancy & 29 & 03.8 \\
Indirect causes & & \\
Anaemia & 93 & 12.1 \\
Meningitis & 13 & 1.7 \\
Hepatic failure & 10 & 1.3 \\
Anaesthetic complications & 5 & 0.7 \\
Other medical diseases & 37 & 4.8 \\
\hline Totals & 767 & 100 \\
\hline
\end{tabular}

Table 4

Annual trends and causes of maternal mortality

\begin{tabular}{|c|c|c|c|c|c|c|c|c|}
\hline Cause of maternal mortality & 2001 & 2002 & 2003 & 2004 & 2005 & 2006 & 2007 & Total \\
\hline Pre-eclampsia/Eclampsia & 18 & 26 & 41 & 41 & 28 & 57 & 34 & 245 \\
\hline PPH & 5 & 10 & 14 & 15 & 8 & 13 & 9 & 75 \\
\hline Placenta praevia & 5 & 9 & 3 & 5 & 9 & 18 & 8 & 57 \\
\hline Abruption placentae & - & - & 8 & 7 & - & - & - & 15 \\
\hline Sepsis & 9 & 12 & 13 & 16 & 6 & 10 & 14 & 80 \\
\hline Ruptured uterus/obstructed & 8 & 9 & 17 & 9 & 5 & 9 & 3 & 60 \\
\hline \multicolumn{9}{|l|}{ labour } \\
\hline Unsafe abortion & 6 & 5 & 8 & 7 & 7 & 6 & 9 & 48 \\
\hline Ruptured Ectopic pregnancy & 2 & 5 & 3 & 5 & 3 & 6 & 5 & 29 \\
\hline Anaemia & 12 & 8 & 12 & 10 & 10 & 21 & 20 & 93 \\
\hline Meningitis & 2 & 3 & 1 & 3 & 1 & 3 & - & 13 \\
\hline Hepatic failure & 3 & 1 & 1 & 2 & 2 & - & 1 & 10 \\
\hline Other medical diseases & 8 & 5 & 3 & 4 & 4 & 5 & 8 & 37 \\
\hline Anaesthetic complications & 2 & - & 1 & - & 1 & 2 & - & 6 \\
\hline Total & 81 & 92 & 125 & 124 & 84 & 150 & 111 & 767 \\
\hline
\end{tabular}

\section{DISCUSSIONS}

This study has revealed that despite the safe motherhood initiatives and seven years into the Millennium Development Goal set up period, maternal mortality, in our environment, is not only high but remains far above the starting benchmark of the year 2000; Nigeria was reported to have an average maternal mortality ratio of 704 in the 2000
(13). Maternal mortality ratio of 1,732 per 1000,000 live births is extremely high and unacceptable. This finding has corroborated recent findings of equally unacceptable maternal mortality ratio in other tertiary centres in Nigeria (1,700/100,000 live births) (15) and $(1,930 / 100,000$ livebirths) (16). This finding may likely represent only just the tip of the iceberg as many cases of maternal deaths do occur without reaching the hospital or any functioning maternity service as 
a result of cultural factors, poverty or inaccessibility of functioning maternity (comprehensive obstetric) service as a result of distance and bad terrain. With the estimated annual total live deliveries of 130,941 in Bauchi state and an average of 6,326 live deliveries at the State Specialist Hospital, there were only $4.8 \%$ of the state live deliveries that took place in the Hospital; which is grossly inadequate as it is the main secondary health facility in the region.

When we consider the MDG expectation of annual reduction of maternal mortality by $5.5 \%$ to achieve the $75 \%$ reduction by the year 2015 , we can see our performances over the years with the year 2001 as our benchmark. We started doing well but over thelast twoyears the figure of maternal mortality ratio has been on the increase with worst increase of maternal deaths in the year 2006. On average, over the seven years period, we were getting the opposite of MDG annual reduction target i.e. increasing our maternal mortality by $5.4 \%$ annually. This should give us more concern on our development efforts, thus making maternal mortality reduction a priority.

This study has shown that maternal deaths are more among the adolescents. This finding partially disagrees with an earlier report; which stated that there are low incidences of maternal death at the extremes of life (17). However it agrees with other reports, which indicated that maternal mortality is highest at the adolescent period $(18,19)$. This may be a result of teenage pregnancy complications (19). It has also been noted that maternal mortality is higher in those of low parity especially the primigravida. This is as a result of high incidence of pregnancyinduced hypertension resulting in preeclampsia and eclampsia with consequent maternal deaths as seen in primigravidas in this series. In this report there was 11 times reduction in maternal mortality in the booked compared to the unbooked. Harrison (4) reported a 22 times reduction in mortality in the booked compared to the unbooked.

Even though haemorrhage was said to be the leading cause of death in Africa (point estimate $33.9 \%$, range 13.3-43.6) (19). The leading cause of death in this study was eclampsia $(31.9 \%)$ this was similar to a previous study in this environment and in Lagos southwestern Nigeria (20,21). Obstetric haemorrhage was the second leading cause of death responsible for $19.2 \%$ of maternal deaths of which $9.8 \%$ died from postpartum haemorrhage and $9.4 \%$ from antepartum haemorrhage. This finding indicated that antepartum haemorrhagenearly equals the postpartum haemorrhage; which is in disagreement with most reports that showed postpartum haemorrhage as being a much more commoner cause of death than antepartum haemorrhage $(17,19)$. Anaemia, even though an indirect cause of maternal mortality, has contributed to $12.1 \%$ of the maternal deaths and for the last three years of the study period, it has been the second highest killer next to eclampsia as a single cause of maternal deaths. The triad of poverty, ignorance and traditional beliefs and practices contributed to create the background for the anaemia in pregnancy and consequent disastrous obstetric outcome for expectant mothers. Malnutrition among the general populace and particularly among the girl-child also play a key role in predisposing our women to anaemia, contracted pelvis leading to obstructed labour, ruptured uterus and postpartum haemorrhages.

The common features in these cases presented were late presentation to the hospital after many hours and sometimes days of commencement of labour. This is manifested by the short period of admission to death interval; as more than $66 \%$ of the patients died within 48 hours of admission. Majority arrived in moribund states from uncontrolled fits and aspiration of gastric contents or concoctions forced on the unconscious patients as in the case of the eclamptics and excessive blood loss leading to irreversible shock in the cases of obstetric haemorrhage. This problem is further compounded by institutional shortcomings as a result of shortage of adequate banked blood for prompt transfusion arising from inefficient blood banking facilities in our hospitals; this is further aggravated by poor response and apathy of patients' relatives to donate blood even in times of dire emergency. These factors complicated the problem posed by haemorrhage. Magnesium sulphate was introduced into the management of eclamptic patients in the hospital in June 2007 perhaps that contributed to the reduction in the number of 2007 maternal deaths from eclampsia compared to the year 2006. Overwhelming sepsis was seen in those who died of sepsis due to late presentation. Having delivered at home following prolonged labour and or in asepticenvironment sepsis easily set in. These patients usually succumbed to infection before the effect of antibiotics could set in and in most cases before the results of bacteriological services were made available.

From the lessons we learnt from this study, we recommend to the Ministry of Health and policymakers to:

(i) Enhance community enlightenment on the magnitude of maternal mortality and the danger signs in pregnant women. Families and communities need to be motivated to take action to save the life of a mother (and her child) when an emergency occurs. More importantly educating the community members on the need for early health seeking behaviours in an appropriate health facility.

(ii) Address unwanted and poorly timed pregnancies and the health risks associated with them. Access to voluntary, safe, affordable, and appropriate family planning information and services is critical to reducing unwanted pregnancies and to reducing the risks of maternal mortality. 
(iii) Improve coverage and quality of prenatal and postpartum care. Prenatal care which includes prevention and / or timely treatmentfor anaemia, malaria, HIV, high blood pressure and other complications is very cost-effective.

(vi) Encourage delayed marriage and first birth for adolescents. This can be achieved by ensuring or advocating for secondary school education for all girls.

(v) Build strong political commitment and enabling policies to ensure and promote cross-sectoral linkages. These include reducing poverty; improving women's education and nutritional status; improving water and sanitation, roads and infrastructure, and transportation.

We, at the State Specialist Hospital Bauchi, as well as those in similar setting, should be poised for managing life-threatening complications in referred patients if the current trend of maternal deaths is to be kept in check. This can be achieved by updating the management policy for eclampsia and focusing attention on enhancement of the quality of emergency obstetric care particularly for the identified leading causes of maternaldeaths. Use of magnesium sulphate, not only in our hospital, but effort must be made in training health personnel from the referring health facilities on the proper use of the drug. Improvement in blood banking and transfusion services and as well as provision of appropriate facilities for managing complicated cases would go a long way in achieving safer motherhood for women in this community.

In conclusion, maternal mortality is unacceptably high in our environment and we are yet to achieve any meaningful success in reducing it. While many factors contribute to maternal death, one of the most effective means of preventing maternal health is to improve health systems; to ensure availability of skilled attendance at all levels and access to 24hour emergency obstetric care. Contextual factors, including poverty, malnutrition and the low status of women, as well as attitudes and behaviours of individuals, the community and providers can positively or negatively influence maternal health.

\section{REFERENCES}

1. World Health Organization (WHO). International Classification of Disease (ICD). 10th revision, 1992: $123-128$.

2. Global estimates of maternal mortality for 1995: result of an in-depth review, analysis and estimation

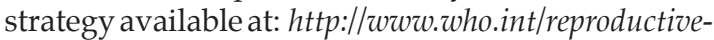
health/p.../statement-on-maternal-mortality-estimates. en.htm.

3. United Nations (UN), World Health Organization (WHO) and World Bank partner to combat maternal mortality. The world bank group news release no. $2000 / 080 / S$.
4. Harrison, K.A. Safe motherhood guest lecture at the annual general conference of the Nigerian medical association. Eko le meridien hotel, Victoria Island Lagos. On Monday 3rd April, 1990.

5. Kawuwa, M.B., Mairiga, A.G. and Usman, H.A. Community perspective of maternal mortality: Experience from Konduga Local Government Area, Borno State, Nigeria. Annals Med. 2007; 6: 109-114.

6. Adamu, Y.M., Salihu, H.M., Sathiakumar, N. and Alexander, G.R. Maternal mortality in northern Nigeria: a population-based study. Eur. J. Obstet. Gynecol. Reprod. Biol. 2003; 109:153-159.

7. Gilda, S., Henshaw, S., Susheela, S., et al. Induced abortion: Estimated rates and trends worldwide. Lancet. 2007. 370: (9595): 1338-1345.

8. WHO, UNICEF, UNFPA. Maternal Mortality in 2000: Estimates Developed by WHO, UNICEF, UNFPA. Geneva: World Health Organization, 2005.

9. United Nations. United Nations Millennium Declaration Resolution adapted by the General assembly, 55th session of the United Nations General assembly, New York September 18, 2000.

10. WHO, UNICEF, UNFPA and the World Bank. Maternal mortality in 2005: Estimates Developed by WHO, UNICEF, UNFPA. Geneva: World Health Organization, 2006.

11. Hill, K., Thomas, K., AbouZahr, C., Walker, N., et al Estimate of maternal mortality worldwide between 1990 and 2005: An assessment of available data. Lancet 2008, 371 (9615): 811-819.

12. National Population Commission(Nigeria), National Population census, 2006. National Population Commission.

13. National Population Commission (Nigeria). Nigeria Demographic and Health Survey 2003. MD: National Population Commission and ORC/Macro, 2004. p 51-60.

14. UNFPA, Programme document between the government of Bauchi state and the UNFPA, 2003, found at: - http://nigeria.unfpa.org/documents/Bauchi state.doc.

15. Agboghoroma, O.C and Emuveyan E.E. Maternal mortality in Lagos, Nigeria: a ten-year review (19861995). Nig. Quart. J. Hosp. Med. 1997; 7: 230-233.

16. Olatunji, A.O. and Sule, O. Maternal Mortality at Sagamu, Nigeria. A ten-year review (1988-1997). The Nig. Postgr. Med. J. 2001; 8: 12-18.

17. Adetoro, O.O. and Okwereku, F.O. Maternal mortality at Ilorin, Nigeria. Trop. J. Obstet. and Gynaecol. 1988; 1: 18-22.

18. Chukwudebelu, W.O. and Ozumba, B.C. Maternal mortality at the University of Nigeria Teaching Hospital, Enugu. A 10-year review. Trop. J. Obstet. Gynaecol. 1988; 1: 23-26.

19. Khalid, S. K., Daniel, W., Lale, S., et al. WHO analysis of causes of maternal death: a systematic review. Lancet. 2006; 367(9516):1066-1074.

20. Olatunji, A.D. and Abudu, O.O. A review of maternal mortality in Lagos University Teaching Hospital (1976-1985). Nig. Med. Pract. 1996; 31 (91/2): 2-6.

22. Bobzom, D.N and Muna, M. Maternal mortality at the State Specialist Hospital, Maiduguri, Borno state. Annals of Borno. 1994/1995. 11/12: 270. 